folk/ed. Derg, 2021; 27(1):135-150

DOI: $10.22559 /$ folklor. 1283

Research Article / Araştırma Makalesi

\title{
Türkiye'deki Edebi Mekânların “Modern Müzecilik" Bağlamında Değerlendirilmesi
}

\section{The Evaluation of Literary Places in Turkey in the Context of "Modern Museology"}

\section{Samet Çevik ${ }^{*}$}

\section{$\ddot{O}_{z}$}

Edebiyat turizminin yapı taşı olan edebi mekânlar, aynı zamanda bir kültürel miras unsuru olarak ön plana çıkmaktadır. Bu mekânlar, ya yazarın hayatının bir kısmını geçirdiği mekân olması ya da yazarın şahsi eşyalarını barındırması nedeniyle ülkelerin önemli edebi ve kültürel miras değerlerini oluşturmaktadır. Edebi mekânların bu değerleri koruma ve gelecek nesillere bırakma işlevi doğrultusunda yönetilmesi gerektiği gibi günümüzün gelişen çağdaş teknolojilerine ayak uydurup toplumun değișen beklentilerine uyum sağlayan bir yönetim anlayışına sahip olmaları da beklenmektedir. Bu çalışmanın amacı, edebi mekânların uygulamalarının "modern müzecilik” bağlamında değerlendirilmesidir. Araştırmanın evrenini Türkiye'de müze statüsünde hizmet veren edebi mekânlar oluşturmaktadır. Çalışmaya 7 edebi mekân (Necati Cumalı Anı ve Kültür Evi; Namık Kemal Evi; Sait Faik Abasıyanık Müzesi; Orhan Kemal Müzesi, Aşiyan Müzesi; Yahya Kemal Müzesi; Rıfat Ilgaz Kültür ve Sanat Evi) dâhil edilmiştir. 2017-2018 yılları arasında bu edebi mekânlardan görüşme ve gözlem yöntemleriyle modern müzecilik uygulamalarına dair veriler toplanmıştır. Modern müzeciliğin gerekli unsurları olan "sunum

* Dr. Öğr. Üyesi. Bandırma Onyedi Eylül Üniversitesi Turizm ve Otel İşletmeciliği. scevik@bandirma.edu.tr. ORCID 0000-0003-0859-6673 / CC BY 
ve anlatım teknikleri”, “eğitim”, "koruma ve restorasyon”, "araştırma, iletişim ve etkinlikler" ve "pazarlama, tanıtım ve sosyal medya" açısından edebi mekanların uygulamaları değerlendirilmiştir. Elde edilen veriler; edebi mekânları günümüz koşullarına uygun hale getirme, toplumla yakınlaştırma ve mekânlara dair farkındalığı artırma yönünde çabaların bulunduğunu ancak bu yolda çeşitli engellerin de olduğunu göstermektedir.

Anahtar sözcükler: edebiyat turizmi, edebi mekânlar, yazar evleri, modern müzecilik, modern müzeciliğin gereklilikleri

\begin{abstract}
Literary places, which are the significant constituent of literary tourism, also come into prominence as an element of cultural heritage. These places constitute important literary and cultural heritage values of the countries either because they are the place where the author spends part of her/his life or because it contains the author's personal effects. While literary places, should be managed in line with the function of preserving these cultural heritage values and sustaining them to the future generations, it is also expected to be managed with an understanding that adapts to the changing expectations of the society by keeping up-to-date with the developing contemporary technologies. The aim of this study is to evaluate the practices of literary places in the context of "modern museology". The population of the research consisted of literary places serving as a museum in Turkey. Seven literary places (NecatiCumalı Memorial and Culture House, Namık Kemal House, Sait Faik Abasıyanık Museum, Orhan Kemal Museum, Aşiyan Museum, Yahya Kemal Museum, Rifat Ilgaz Culture and Art House) were included in the study. Between 2017 and 2018, data on modern museum practices were gathered through interviews and observations from these literary places. The practices of literary places are evaluated in terms of "presentation and expression techniques", "education", "conservation and restoration", "research, communication and events", "marketing, promotion and social media", which are essential elements of modern museology. The data obtained shows that there are efforts made to bring literary places up-to-date, to integrate with society, and to raise awareness about museums, but there are various obstacles in this way.
\end{abstract}

Keywords: literary tourism, literary places, author-related houses, modern museology, necessities of modern museology

\title{
Extended summary
}

Modern museology is a holistic approach that includes the selection, maintenance, exhibiton methods, promotion, education oriented programs, researches to integrate the museum with the society, and public relation studies. In this study, modern museology is dealt with in terms of literary places, which are also cultural heritage elements. As a type of literary 
tourism, these places linked to the author can create attractive elements for visitors who have an inner interest in the life stories of the authors. Visits to these places enable to witness the memories of the authors admired, get in touch with their personal belongings, and the environment of the place increases the experiential quality of such contacts.

The first literary museum in Turkey is Aşiyan Museum, where Tevfik Fikret lived between the years 1906-1915. The museum was opened to service in 1945 under the name "Edebiyat-1 Cedide Museum". In the following years; in İstanbul Sait Faik Abasıanık Museum, Yahya Kemal Museum, Hüseyin Rahmi Gürpınar Museum, Kemal Tahir Museum House, Orhan Kemal Museum, Haldun Taner Museum House; in Ankara Mehmet Akif Ersoy House; in İzmir Necati Cumalı Memorial and Culture House; in Diyarbakır Cahit Sitkı Taranc1 Museum and Ziya Gökalp Museum; in Hatay Cemil Meriç Museum; in Tekirdağ Namık Kemal House and in Kastamonu Rifat Ilgaz Culture and Art House started to service. 7 out of these literary places (Necati Cumalı Memorial and Culture House, Namık Kemal House, Sait Faik Abasıyanık Museum, Orhan Kemal Museum, Aşiyan Museum, Yahya Kemal Museum, Rifat Ilgaz Culture and Art House) were included in the study. Between 2017 and 2018, data on modern museum practices were gathered with interview and observation methods from these literary places. The practices of literary places are evaluated in terms of "presentation and expression techniques", "education", "conservation and restoration", "research, communication and events", "marketing, promotion and social media", which are essential elements of modern museology.

In terms of presentation and expression techniques, literary places have generally adopted techniques that are more traditional and do not contain much technology. Personal guidance services, panels or explanations written under objects are the most used methods. In the field of education, which is one of the most important issues of modern museology, all literary places have an important occupation. Student groups constitute the largest target audience of literary places. In the field of conservation and restoration; it is understood that almost all literary places have undergone a comprehensive restoration and during the restoration process, the places remained as faithful to their original form as possible. In terms of research, communication and events, it is seen that literary places do not have much communication with other museums and do not lead their staff in this direction. However, literary places make efforts in terms of integrating with the society and to raise awareness of both the literary place and the author in society through various events. Although marketing and promotional activities in modern museology are very significant and should be undertaken by a seperate unit, it is revealed that there is no a seperate unit for these activities in literary places and the internet or social media is not actively used in most literary places.

The managers make efforts to adopt museums to today's conditions, to bring them closer to the society and to increase awareness about museums, but they encounter various obstacles in this way. The most important of these obstacles is the budget problem. Literary places do not have a high budget, as they are generally affiliated to units such as municipalities or associations and serve as non-profit organizations. Therefore, costly efforts such as the use of new technologies within the museum, effective promotion and advertising activities are 
forcing literary places.

Managers of places; since they are not the sole decision-maker for any event, promotion or cooperation, they may be obliged to obtain permission from the units they are affiliated with or to implement their decisions. This situation is one of the factors that constitute an obstacle in the development of literary places. The low number of staff in literary places is also one of the important factors that causes many works to be put into the background. Most literary places have one or two staff who can only deal with routine works. The absence of positions such as education unit specialist, social media expert that should be in modern museums in literary places also constitutes an obstacle to the professional management of these places.

It should not be forgotten that literary places are a cultural heritage value of countries, especially the cities they are located in. The literary places that keep the literary heritage left by the authors should focus on the works of transferring this heritage to the future generations in its original form, on the other hand, they should have a professional management that adapts to the changing expectations of the society and accommodates today's contemporary technologies as much as possible.

\section{Giriş}

Eserlerin sergilenmesi, verilen hizmetler, toplumun ilgisi, işlevsellik, yönetim, mimari ve nitelik bakımından müzeler önemli bir değişim ve dönüşüm geçirmektedir. Bu değişime ayak uyduran, kendini yenileyen ve ziyaretçilerini tatmin edecek daha etkili ve çekici ortamlar oluşturan müzeler daha fazla tercih edilmektedir (Kervankıran, 2014). Müzeler, 20. yüzyılın ortalarına kadar eserlerin toplanması, korunması ve sergilemesini kapsayan klasik bir anlayışa sahipken küreselleşme olgusuyla birlikte teknolojide yaşanan gelişmeler ve kültür kavramına olan bakışın değişmesiyle modern müzecilik yaklaşımıyla ele alınmaya başlamıştır (Altunbaş ve Özdemir, 2012). 20. yüzyılın ortalarından itibaren müzelerde koleksiyonların toplumun her kesimiyle buluşması için türlü yöntemler geliştirilmeye başlanmıştır. 1950'lerden itibaren bireye ve topluma yönelik alanlarda uzmanlarla çalışma ihtiyacı doğmuştur. Müzelerde iletişim, tasarım ve eğitim alanlarında da uzman personelin bulundurulması gerekliliği önem kazanmıştır (Atagök, 2010).

Uluslararası Müzeler Konseyi'nin (ICOM) zaman içinde güncellemiş olduğu “müze” tanımlarından da müzeciliğin geçirmekte olduğu değişim ve dönüşümün anlaşılması mümkündür. ICOM, 1946-2007 yılları arasında "müze" kavramına ilişkin sekiz farklı tanımlamaya gitmiştir. 1946 y1lında müzeler; hayvanat bahçeleri ve botanik bahçelerinin de dâhil olduğu, ancak sürekli sergi salonu bulunmayan kütüphanelerin hariç tutulduğu, sanatsal, teknik, bilimsel, tarihi veya arkeolojik koleksiyonları içeren tüm halka açık mekânlar şeklindedir. 1951 yılında müzelerin koruma, çalışma, geliştirme ve özellikle kamuoyuna nesnelerin ve kültürel değer örneklerinin eğitim ve haz vermek için sergileme amaçlarını güden kurumlar oldukları eklenerek müzelerin işlevlerine dair de bir bakış açısı kazandırılmıştır. 1961 yılın- 
da müzelerin amaçları arasında yine çalışma, eğitim ve eğlence vurgulanırken 1974 yılında müzelerin kar amacı gütmeyen, topluma ve toplumun kalkınmasına hizmet eden kurumlar olduklarına dikkat çekilmiştir. 1989 yılında, yapılan son tanımın evrenselliği vurgulanmıştır. 1995 ve 2001 yıllarında müzelerin insanların çeşitli amaçlarla ihtiyaç duydukları maddi kanıtları edinen, araştıran, iletişim kuran ve sergileyen kurumlar olduklarına değinilmiştir. 2007 yılında yapılan tanımda ise müze, “eğitim, çalışma ve eğlence amaçlarıyla insanlığın ve çevresinin somut ve somut olmayan kültürel mirasını edinen, koruyan, araştıran, iletişim kuran ve sergileyen, topluma ve toplumun kalkınmasına hizmet eden, halka açık, kar amacı gütmeyen ve sürekliliği olan kuruluş" şeklinde tanımlanmıştır (ICOM, 2007). Bu son tanımda müzelerin sürekliliği olan kuruluşlar oldukları vurgulanırken aynı zamanda somut olmayan kültürel mirasa da ilk kez müze tanımı kapsamında yer verilmiştir. Bu da müzelerin hem işlev hem de kapsam olarak değişen yapısını göstermesi bakımından önem arz etmektedir.

Bu çalışmada modern müzecilik, aynı zamanda birer kültürel miras unsuru olan edebi mekânlar özelinde ele alınmıştır. Edebiyat turizminin bir çeşidi olarak yazarla bağlantılı bu mekânlar, yazarların hayat hikâyelerine içsel bir ilgi duyan ziyaretçiler için çekicilik unsurları oluşturabilmektedir. Bu mekânlara yapılan ziyaretler, hayranlık duyulan yazarların hatıratına tanıklık etmeyi, kişisel eşyalarıyla temasa geçmeyi sağlamakta ve mekânın ortamı bu tür temasların deneyimsel kalitesini artırmaktadır. Bu mekânlar aynı zamanda birer kültürel miras unsuru olarak turistik destinasyonların da önemli çekiciliklerinden sayılmaktadır.

\section{Modern müzecilik}

Modern müzecilik, müzeye girecek eserlerin seçimi, bakımı, sergileme yöntemleri, tanıtımı, eğitim odaklı programlar, müzeyi toplumla bütünleştirme yönünde yapılan araştırmalar ve halkla ilişkiler çalışmalarını kapsayan bütüncül bir yaklaşımdır. Keleş (2003: 6) günümüz modern müzeciliğinde dört önemli yaklaşımın bulunduğundan bahsetmiştir. Bunlar; "sanal müze", "dokunulabilir müze", "mobil müze" ve "vakıf müzeciliği”" yaklaşımlarıdır. Sanal müzecilik, müzelerin modern teknolojileri kullanarak sahip oldukları koleksiyonları ve sergileri geniş kitlelere hızlı bir şekilde ulaştırmalarına imkân tanımaktadır. Sanal müzeler, elektronik ortamda erişilebilen görsel, ses ve metin dosyalarını sanat, kültür ve tarih alanında insanlarla paylaşan dijital hazinelerdir. Bu anlamda modern müzelerin bilginin sunulduğu ya da korunduğu ortamdan çok bilginin paylaşıldığı mecralar olarak ön plana çıktığı söylenebilir (Barlas Bozkuş, 2014: 330). Modern müzeler çağdaş iletişim teknikleriyle sahip olduklarını insanlara ulaştıran "mobil müzecilik" anlayışına yönelmektedirler. Ayrıca yapılan çeşitli etkinliklerle müzeler hedef kitlelerini genişletmeye yönelmekte ve müze gezme alışkanlığı olmayan kesimlere ulaşarak "dokunulabilir müzecilik" yaklaşımıyla hareket etmektedirler. $\mathrm{Bu}$ yaklaşım aynı zamanda eğitimin modern müzeciliğin temel yapı taşlarından biri olduğunu göstermektedir (Keleş, 2003).

Modern müzecilik açısından önemli konulardan biri sunum ve anlatım teknikleridir. Sergileme; müze türlerine göre farklılık göstermekle birlikte müzenin amacı, koleksiyonu, 
vermek istediği mesaj ya da hedef kitle profili gibi unsurlardan da etkilenmektedir (Boyraz, 2013). Günümüzde modern müzecilik kavramı içinde geleneksel yöntemlerin yanı sıra teknolojik araçlardan yararlanılarak yapılan gösterimler de ziyaretçilere sunulmaktadır. Müzelerde durağan ve dinamik sergileme teknikleri çeşitli şekillerde kullanılmaktadır. Durağan sergileme ve sunum teknikleri arasında vitrin içi sergileme, panolar, stant üzeri sergileme, diyaromalar, maketler, modeller (mankenler ve mumyalar), kopyalar, slayt gösterileri yer almaktadır. Dinamik sergileme ve sunum teknikleri ise gösteri odaları, dokunmatik ve interaktif sistemler, planetaryum, panorama, robotlar, canlandırma, IMAX dijital sunumlar, hologramlı sunumlar gibi özel hazırlanmış düzenekler gerektiren gösterimleri içermektedir (Erbay, 2011).

Modern müzecilik anlayışında eğitim, müzenin üstlendiği temel işlevlerin başında gelmektedir. Günümüzde müzeler; araştırmacılık, gözlem, yaratıcılık, hayal gücü ve beğeni duygusunun oluşmasına ve gelişmesine katkıda bulunabilecek eğitim kurumları olarak benimsenmişlerdir. Müzeler; sergilenen eserleri anlayıp kavrayabilen, yorumlayan, estetik beğenisi olan izleyici kitlesinin oluşturulmasını sağladıkları gibi aynı zamanda yaratıcılığın geliştirilmesinde de rol oynarlar. Müzeler eğitimin öğrenciler için örgün eğitimle bağlantılı olarak ve ayrıca okul dışında; yetişkinler için de okul sonrasında devam etmesini sağlamaktadır. Bu yüzden eğitim departmanları, birimleri, yöneticileri ve elemanları müzelerin olmazsa olmaz unsurları arasındadır. Bu kapsamda müzelerin diğer eğitim-öğretim kurumları ile işbirliği yapmaları söz konusudur (Karabıyık, 2007; Okan, 2015).

Koruma işlevi modern müzeciliğin de önemli işlevlerinden birisidir. Modern binalarda koleksiyonun muhafazası için tasarım çalışmaları daha kolay olabilmekteyken özellikle ülkemizde müze olarak kullanılan çoğu binanın tarihi bir değere sahip olması ya da eskiden başka bir amaçla kullanılırken günümüzde müzeye dönüştürülmesi gibi sebeplerle bu konuda birçok zorluk belirebilmektedir (İnel, 1998'den aktaran Altunbaş ve Özdemir, 2012). Ülkemiz müzelerinin çoğu eski mimariye sahip tescilli yapılardan oluşmakta ve bu yapılar üzerinde büyük değişiklikler yapılamamaktadır. Müze binası olarak tasarlanmayan yapılarda eser vitrinleri, bina mimarisine uydurulmaya çalışıldığında eserin görüntüsü olumsuz etkilenebilmektedir. Kimi zaman da eser, yapının gölgesinde kalabilmektedir (Ersoy, 2016).

Modern müzecilikte müzelerin birbirleriyle iletişim kurması ve işbirlikleri önemlidir. Personelin belli dönemlerde diğer müzelere giderek bilgi paylaşımında bulunması, çağdaş tekniklerin hızlı bir biçimde yayılmasını sağlamaktadır. Böylece müzeler arası araştırmaların yaygınlaşması da olanak bulabilmektedir (Altunbaş ve Özdemir, 2012). Ayrıca modern müzeler, hedeflerine ulaşmak için başlıca yöntem olarak iletişim ve halkla ilişkilere yönelmektedir. Müzeler yaptıkları etkinlikleri geniş kitlelere ulaştırmak ve toplumun ilgisini çekmek durumundadırlar. Bu nedenle modern müzeler hedef kitlesini genişletmek için bilinçli programlar ve çeşitli iletişim araçlarıyla halka ulaşmak durumundadır (Karabıyık, 2007). $\mathrm{Bu}$ kapsamda müzeler, toplumun farklı kesimlerini hedef alan çeşitli etkinlikler gerçekleştirmektedirler. Söyleşiler, dinletiler, çocuklar ya da yetişkinler için atölyeler modern müze etkinlikleri arasında yer almaktadır (Okan, 2015). 
Modern müzeler açısından veri tabanı oluşturmak ve envanter yazılımları kullanmak gerekli olduğu kadar (Okan, 2015) müzelerin pazarlama ve tanıtım çalışmalarına önem vererek internet ve sosyal ağları da etkili bir biçimde kullanmaları önem arz etmektedir. Bu nedenle günümüzde müze yöneticileri tarafından daha geniş kitlelere ulaşabilmek için halkla iletişim birimleri kurulmakta, kitap, afiş ve broşür gibi yayınlar basılmaktadır. Ayrıca teknolojik gelişmeyle birlikte mobil uygulamalar geliştirilmekte, dinamik haritalar üretilmekte ve sosyal medya aracılığı ile müzelerin tanınırlığının artırılması için planlamalar yapılmaktadır (Kervankıran, 2014).

\section{Modern müzecilik açısından Türkiye'deki edebi mekânlar}

Türkiye'de açılan ilk edebi müze, İstanbul'da bulunan Aşiyan Müzesidir. Tevfik Fikret'in 1906-1915 yılları arasında yaşadığı ev, 1940 yılında İstanbul Belediyesi tarafından satın alınmış ve 1945 yılında Edebiyat-1 Cedide Müzesi olarak hizmet vermeye başlamıştır (İstanbul İl Kültür ve Turizm Müdürlüğü, 2019). Sonraki yıllarda İstanbul'da Sait Faik Abasıyanık Müzesi, Yahya Kemal Müzesi, Hüseyin Rahmi Gürpınar Müzesi, Kemal Tahir Müze Evi, Orhan Kemal Müzesi, Haldun Taner Müze Evi; Ankara'da Mehmet Akif Ersoy Evi; İzmir'de Necati Cumalı Anı ve Kültür Evi; Diyarbakır'da Cahit Sıtkı Tarancı Müzesi ve Ziya Gökalp Müzesi; Hatay'da Cemil Meriç Müzesi; Tekirdağ'da Namık Kemal Evi ve Kastamonu'da Rıfat Ilgaz Kültür ve Sanat Evi gibi edebi mekânlar hizmet vermeye başlamıştır.

Çalışma kapsamına yedi edebi mekân dâhil edilmiş olup bu evlerin yetkilileri ile yapılan görüşmeler ve gözlem sonucu elde edilen bilgiler ışığında edebi mekânların modern müzecilik uygulamalarına dair veriler toplanmıştır. 4 Ağustos 2017 tarihinde Necati Cumalı Kültür ve Sanat Evi; 14 Ağustos 2017 tarihinde Namık Kemal Evi; 16 Ağustos 2017 tarihinde Sait Faik Abasıyanı Müzesi; 24 Kasım 2017 tarihinde Orhan Kemal Müzesi; 30 Mart 2018 tarihinde Aşiyan Müzesi; 4 Mayıs 2018 tarihinde Yahya Kemal Müzesi ve 8 Ağustos 2018 tarihinde Rlfat Ilgaz Kültür ve Sanat Evi yetkilileri ile görüşmeler gerçekleştirilmiştir. Elde edilen veriler, modern müzeciliğin gerekli unsurları olan "sunum ve anlatım teknikleri", "eğitim”, "koruma ve restorasyon", "araştırma, iletişim ve etkinlikler", "pazarlama, tanıtım ve sosyal medya" başlıkları altında sınıflandırılarak sunulmuştur.

Sunum ve anlatım teknikleri: Edebi mekânların çoğunda verilmek istenen mesaj yazarın anısını yaşatmak, hayatı ve eserleri hakkında ziyaretçilere bilgi vermektir. Necati Cumalı Anı ve Kültür Evi, Sait Faik Abasıyanık Müzesi ve Orhan Kemal Müzesi tamamen bu amaca yönelik olarak düzenlenmiş olup sadece yazarın hayatıyla ilişkili obje ve belgeleri sergilemektedir. Yahya Kemal Müzesi de yazarın edebi ve kişisel hayatının önemli unsurlarını sergilemektedir ancak müzenin bir bölümü de müze fikrinin yaratıcısı olan ve koleksiyonun biraraya getirilmesini sağlayan Nihat Sami Banarlı'nın hatırasına ayrılmıştır. Aşiyan Müzesi, Tevfik Fikret'in kendi yaptırdığı ve 1906-1915 yılları arasında yaşadığı ev olmakla birlikte 1945 yılında "Edebiyat-1 Cedide Müzesi” olarak açılmış ve Tevfik Fikret ile birlikte çok sayıda edebiyat ustasına yer verecek şekilde düzenlenmiştir. Günümüzde de Aşiyan Müzesi, 
ağırlıklı olarak Tevfik Fikret'in anısını yaşatmak amacını güdüyor olsa da bazı bölümler Abdülhak Hamit Tarhan, Şair Nigar gibi edebi isimlere ayrılmıştır. Namık Kemal Evi ile Rıfat Ilgaz Kültür ve Sanat Evi ise sergileme kararlarında yazarın anısını yaşatma amacı dışında aynı zamanda yazarın bağlı olduğu yörenin çeşitli etnografik değerlerini de sergileyerek bir “etno-edebi müze” şeklinde hizmet vermektedir.

Sunum ve anlatım teknikleri açısından edebi mekânlar değerlendirildiğinde genellikle daha geleneksel olan ve teknolojiyi çok fazla barındırmayan tekniklerin benimsendiği görülmektedir. Kişisel rehberlik hizmetleri, büyük panolar ya da objelerin altına yazılan açıklamalar en çok kullanılan yöntemlerdir.

Her gelen konuğa kişisel rehberlik hizmetinin sunulduğu edebi mekânlar; Necati Cumalı Anı ve Kültür Evi, Yahya Kemal Müzesi, Orhan Kemal Müzesi ve Aşiyan Müzesidir. Yahya Kemal Müzesi, bu hizmeti gönüllü üniversite öğrencileri aracılığıyla gerçekleştirmekte ve istenildiğinde yabancı dilde de rehberlik hizmeti vermektedir. Orhan Kemal Müzesinin önemli bir farkı, Orhan Kemal'in oğlu Sayın Işık Öğütçü’nün birinci ağızdan babasının hayatından kesitleri, anıları sunuyor olmasıdır. Sait Faik Abasıyanık Müzesinde münferit ziyaretçilere rehberlik hizmeti sunulmamakla birlikte gruplara rehberlik hizmeti verilmektedir. Aşiyan Müzesinde ayrıca sesli rehberlik hizmeti sunulmaktadır.

Edebi mekânlar tarafından en çok tercih edilen diğer anlatım teknikleri, büyük panolar ve obje altı etiketlemedir. Bu yöntemler rehberlik yöntemine kıyasla daha sınırlı bilgi sunmakta ve çift yönlü iletişime izin vermemektedir ancak, ziyaretçilerin belli bir düzeyde bilgilenmesine imkân tanımaktadır. Necati Cumalı Anı ve Kültür Evi ve Sait Faik Abasıyanık Müzesi pano sistemini etkin bir şekilde kullanarak bilgi verme fonksiyonunu yerine getirmektedir. Necati Cumalı Anı ve Kültür Evinde her oda isimlendirilerek oda girişlerine Türkçe ve İngilizce dillerinde tabelalar asılmıştır. Ayrıca her objenin altında Türkçe dilinde açıklamalar mevcuttur. Sait Faik Abasıyanık Müzesi ve Aşiyan Müzesinde etiketleme sistemi Türkçe ve İngilizce dillerinde uygulanmaktadır. Orhan Kemal Müzesi, Namık Kemal Evi, Rlfat Ilgaz Kültür ve Sanat Evinde ise sadece Türkçe açıklamalar mevcuttur.

Sunum ve anlatım teknikleri açısından edebi mekânlarda teknolojinin kullanıldığı alanların sınırlı olduğu görülmektedir. Aşiyan Müzesindeki sesli rehberlik uygulaması dışında ses ve görüntünün kullanıldı̆̆ı teknikler süreklilik göstermemektedir. Orhan Kemal Müzesinde önceleri Orhan Kemal'in sesinin kullanıldığı fakat daha sonra iptal edildiği belirtilmiştir. Yahya Kemal Müzesinde de ses kayıtları bulunmakta ancak dönemin koşulları gereği kayıtların kötü olmasından dolayı ziyaretçilere sunulamamaktadır. Müzede, öğrenci gruplarına yarım saatlik bir video sunumu gerçekleştirilmektedir. Sait Faik Abasıyanık Müzesinde de gruplar için talep olduğunda etkinlik salonunda belgesel gösterimi yapılmaktadır.

Ĕ̆itim: Modern müzeciliğin en önemli alanlarından biri olan eğitim alanında tüm edebi mekânların önemli derecede bir uğraşları söz konusudur. Öğrenci grupları, edebi mekânların en büyük hedef kitlesini oluşturmaktadır. Bu mekânlarda modern müzecilikte olması gerektiği gibi sadece eğitim fonksiyonuyla ilgilenen ayrı bir birim olmamakla birlikte müze 
yetkililerinin okullarla ve çeşitli kurumlarla etkin işbirliklerine büyük önem vererek öğrenci gruplarını müzede ağırlamaya çalıştıkları anlaşılmaktadır.

Necati Cumalı Anı ve Kültür Evini Urla ve İzmir'deki okullar, özellikle nisan ayından itibaren ziyaret etmektedirler. Genellikle okulların, gezileri farklı öğrencilerle sürekli olarak tekrar ettikleri belirtilmiştir. Namık Kemal Evi, özellikle nisan, mayıs ve haziran aylarında yoğun bir şekilde öğrenci grupları tarafından ziyaret edilmektedir. Grupların büyük çoğunluğunu Tekirdağ' daki okullar oluşturmakla birlikte özellikle Ankara'dan, İzmir'den ve çevre illerden de gezilerin gerçekleştirildiği belirtilmiştir. Sait Faik Abasıyanık Müzesine özellikle nisan-mayıs ve eylül-ekim aylarında düzenli olarak İstanbul'dan gelen okullar bulunmaktadır. Müze, diğer edebi mekânlardan farklı olarak çocuklara yönelik, akıllı telefonlara yüklenen bir program aracılığıyla eğitim amaçlı oyunlar da sunmaktadır. Orhan Kemal Müzesini de eğitim-öğretim dönemlerinde yoğun bir şekilde okullar ziyaret etmektedir. Müze, çeşitli işbirlikleriyle daha fazla sayıda okula ulaşmayı hedeflemektedir. Aşiyan Müzesi, eğitim anlamında hem lise ve dengi okullar hem de üniversiteler tarafından ekim ayından haziran sonuna kadar ziyaret edilen bir müzedir. Müzenin eğitim fonksiyonuna çok önem veren müze yönetimi, Tevfik Fikret'in de çok yönlü bir kişilik olması nedeniyle, gelen öğrencilerin okudukları bölüm ve ilgi alanlarına göre anlatımı şekillendirmektedir. Müzede daha küçük yaştaki öğrenci grupları için müze anlatımının yanı sıra müze nedir, işlevleri nelerdir, bir müze nasıl gezilir gibi temel konularda bilgilenmelerini sağlayacak anlatımlar da yapılmaktadır. Yahya Kemal Müzesini ise öğrenci kulüpleri vasıtasıyla daha çok üniversite öğrencileri ziyaret etmektedir. Müze, öğrenci grupları için randevu sistemiyle çalışmakta ve rehberlik hizmetinin yanı sıra yazarın hayatını, edebi kişiliğini anlatan video sunum da gerçekleştirmektedir. Rlfat Ilgaz Kültür ve Sanat Evi de başta Kastamonu olmak üzere çevre illerden okulların ve üniversite öğrencilerinin düzenlediği gezilerin yoğun olduğu bir edebi mekândır.

Koruma ve restorasyon: Koruma ve restorasyon alanında edebi mekânlar incelendiğinde hemen hemen bütün mekânların kapsamlı bir restorasyondan geçtiği ve restorasyon sürecinde mekânın orijinal haline mümkün olduğunca sadık kalındığı anlaşılmaktadır.

Necati Cumalı Anı ve Kültür Evi olarak hizmet veren Necati Cumalı'nın İzmir'in Urla ilçesinde bulunan baba evi, 1985 yılında yol genişletme çalışmaları nedeniyle yıkılmıştır. Takip eden yıllarda Urla Belediyesi tarafından rekonstrüksiyon çalışmalarına başlanmıştır. Otantiklik açısından bakıldığında evin, aslına mümkün olduğunca yakın şekilde yeniden inşa edildiği anlaşılmaktadır. Evde sergilenen objeler açısından ise evin otantiklik beklentilerini karşıladığ1 görülmektedir, çünkü sergilenen eşyaların birçoğu yazarın şahsına ait olup ölümünden sonra eşi Berin Hanım tarafından İstanbul'daki evlerinden getirilmiştir. "Çalışma Odası" ismiyle düzenlenmiş odada yazarın çalışma masasını, daktilosunu, pikabını, fotoğraf makinesini görmek mümkündür. Bu eşyalar için şerit ya da camekân gibi herhangi bir koruma önlemi alınmamakla birlikte çeşitli uyarı yazıları bulunmaktadır. Yazarın pasaportu, kimliği, evlenme cüzdanı, lise fizik defteri, askerlik, sünnetlik ve çocukluk fotoğrafları, havan koleksiyonu, oyun takımları, kahve fincanı gibi kişisel eşyaları ise camlı bölmeler ardında sergilenmektedir. 
Namık Kemal Evi, Namık Kemal'in anısını yaşatmak amacıyla 1992 yılında 18. ve 19. yüzyıl Osmanlı mimarisi tarzında üç kat olarak inşa edilmiştir. Namık Kemal'in hiçbir kişisel eşyası bulunmadığından evin, otantiklik anlamında edebiyat turistlerinin beklentilerini karşıladığını söylemek pek mümkün değildir. Ancak ev, etno-edebi bir müze şeklinde tasarlandığından Tekirdağ'ın geleneksel kültürüne ait olan ve çoğu 100-150 yıllık bir geçmişe uzanan pek çok objeyi barındırmakta ve kültürel mirası koruma anlamında önemli bir işlevi yerine getirmektedir.

Sait Faik Abasıyanık Müzesi, 2013 yılına kadar eski sistemle müzecilik anlayışına devam etmiş, 2013 yılında ise yenilenmiştir. Bu yenilemenin, bütün teknolojik imkânların ve yeni müzecilik teknolojilerinin kullanılarak yapıldığı ancak, bu düzenlemede sağlamlaştırma ve bazı düzenlemeler haricinde evin, eşyaların orijinalitesine dokunulmadığı belirtilmiştir. 1938 yılından itibaren Sait Faik'in annesiyle birlikte yaşadığı bu ev, yazarın ölümünden kısa bir süre sonra ve annesi hayattayken 1959 yılında müze olarak açılmıştır. Müze, annesinin vasiyeti üzerine sadece Sait Faik'in hayat hikâyesine odaklanmış olup son restorasyon itibariyle de bu vasiyet doğrultusunda yazara dair eşyalar, belgeler ve hatıraları sergilemeye devam etmektedir. Müze, hem yazarın yaşadığı ev hem de sergilenen eşyaların yazara ait olması nedeniyle otantiklik açısından avantajlı bir konumda bulunmaktadır. Okul evrakları, lise diploması, İstanbul Üniversitesi kimliği, orijinal el yazmaları, pasaportu gibi belgeler, koruma amaçlı camlı bölmelerde yer alırken eşyalar da ziyaretçilerin geçişini engellemek amacıyla camekân ardında sergilenmektedir.

Orhan Kemal Müzesi binası Orhan Kemal'in yaşadığı yer olmayıp oğlu Sayın Işık Öğütçü tarafından yazarın edebi hatırasını yaşatmak amacıyla açılmıştır. Sergilenen pek çok obje, yazara ya da aile bireylerine aittir. Müzede sergilenen küçük objeler, belgeler ve kitaplar camlı bölmelerde ve panolarda koruma altına alınmıştır. Orhan Kemal'in çalışma odasını tasvir eden bölümde bulunan; yazarın çalışma masası, yatağı, tüm eserlerini yazdığı daktilosu gibi kişisel eşyaları ise zincirden bir şeritle ziyaretçi geçişine engellenmiştir.

Aşiyan Müzesi, Edebiyat-1 Cedide Müzesi olarak açıldığı 1945 tarihi öncesinde de bir restorasyondan geçmiş ve sonraki yıllarda da müzede çeşitli düzenlemeler yapılmıştır. Müzenin günümüzdeki yetkilisi, geçmişteki bu bakımlar sırasında kalem işlerinin sıva altında kalması, duvar renklerinin özgünlügüünü kaybetmesi, bazı bölmelerin bakımsız kalması, banyoda, mutfakta, çamaşırhanede değişikliklerin yapılması, orijinal taşların üzerine ahşapların döşenmesi gibi evin özgünlüğünün kaybolmasına yol açan pek çok değişikliğin yapıldığından bahsetmiştir. 2010 yılında alınan kararla müze kapsamlı bir restorasyondan geçirilmiştir. Bu restorasyon sırasında ciddi bir arşiv araştırması yapılmış ve evin ilk dönemi olan 1910'lardaki haline yaklaşılmaya çalışılmıştır. Bunu sağlamak için arşivdeki fotoğraflar, birçok kişinin evle ilgili anıları ve kitaplardan yararlanılmıştır. Özellikle Tevfik Fikret'in bizzat kendisinin çekmiş olduğu ve 2005 yılında bir müzayededen temin edildiği belirtilen 20'ye yakın fotoğrafın evin özgün haline yaklaşılmasında çok faydalı olduğu belirtilmiştir. Ayrıca Ruşen Eşref Ünaydın'ın 1919'da yazdığı “Tevfik Fikret: Hayatına Dair Hatıralar” kitabında evle ilgili verilen ince detaylardan da büyük ölçüde yararlanılmıştır. Elde edilen bulgular 
1şığında mevcut olan orijinal eşyalar orijinal yerlerine konmuş ve evin Fikret dönemindeki bütün bölmeleri sergilemeye açılmıştır. Müze olarak açılmadan önce evin Tevfik Fikret'in eşi tarafından pansiyon olarak kullandırıldığı zamanlarda birçok eşyanın yok olması sonucu bazı parçalar replika olarak yapılmıştır. Müze yetkilisi, replikaların yapılmasına çok itina gösterdiklerini ve birebir benzemelerini sağladıklarını belirtmiştir. Evdeki tabloların bazılarının önünde çiçekler mevcut olup bunun nedeninin ziyaretçilerin tablolara yaklaşmaması için alınmış bir önlem olduğu belirtilmiştir. Müzede fotoğraf çekimine izin verilmemektedir.

Yahya Kemal Müzesinin bağlı olduğu Fetih Cemiyeti, müzenin açıldığ1 1961 tarihinde başka bir binada hizmet vermekte olup sonraki yıllarda Kara Mustafa Paşa Medresesi'nin Sıbyan Mektebi kısmının restore edilerek müze haline dönüştürülmesiyle günümüzde hizmet verdiği bu binaya taşınmıştır. Yahya Kemal, hayatının son 20 yılını Park Otel'de geçirdiğinden bu binayla herhangi bir ilgisi bulunmamaktadır. Sabit bir yerde yaşamadığı için çok fazla kişisel bir eşyası da bulunmayan Yahya Kemal'in otel odasındaki eşyaları, şahsına ait belgeleri Nihat Sami Banarlı tarafından müze için toplanmıştır. Dolayısıyla müze; yazarın kullandığ 1 objeler, kıyafetler, kitaplar gibi sergilenen eşyalar bakımından otantiklik beklentilerine cevap vermektedir. Bu eşyalar ve belgeler koruma amaçlı olarak camekân içerisinde sergilenmektedir. Yazarın el yazıları gibi bazı belgelerin ise orijinalleri sergilenmemekte, bunun yerine fotokopileri kullanılmaktadır. Binanın tarihi bir yapı olması nedeniyle rutubet problemi yaşandığı için böyle bir yola başvurulmuştur. Belgelerin orijinal versiyonları ise müzede klasörler içinde muhafaza edilmektedir. Müze binasının önümüzdeki süreçte kapsamlı bir restorasyona alınacağı ve bu tür problemler için köklü çözümler üretileceği belirtilmiştir. Ayrıca müzede fotoğraf çekimine kesinlikle izin verilmemektedir.

Rıfat Ilgaz’ın doğduğu ve Rlfat Ilgaz Kültür ve Sanat Evi olarak hizmet veren ev, uzun yıllar boyunca atıl durumda kalmış, daha sonra bakanlık tarafından satın alınarak aslına uygun bir şekilde restorasyon çalışmaları başlatılmıştır. Bu edebi mekân, hem yazarın doğduğu ev olması hem de evde sergilenen eşyaların bir kısmının yazarın şahsına ait olması nedeniyle otantiklik açısından şanslı bir konumdadır. Yazarın şahsına ait olan yatak, kıyafetler, tablolar, televizyon, kitaplık, radyo, daktilo, çeşitli kişisel objeler gibi eşyalar İstanbul'daki evinden getirtilmiştir. Rıfat Ilgaz Kültür ve Sanat Evi, ayrıca Cide’nin geleneksel kültürünü tanıtan unsurlara da yer verdiğinden kültürel mirasın korunması ve sürdürülebilirliğine de katkı sağlamaktadır. Bazı belgeler ve yazarın çeşitli kişisel eşyaları camlı bölmeler ardında sergilenmekte olup ayrıca eşyaların bulunduğu odalarda da ziyaretçi geçişini engelleme amaçlı şeritler kullanılmaktadır.

Araştırma, iletişim ve etkinlikler: Araştırma, iletişim ve etkinlikler anlamında edebi mekânların, diğer müzelerle çok fazla iletişiminin olmadığı ve personelini bu doğrultuda yönlendirmediği görülmektedir. Ancak toplumla yakınlaşma ve bütünleşme açısından edebi mekânların çaba harcadığı ve mümkün olabildiğince bir halkla ilişkiler aracı olarak çeşitli etkinliklerle hem edebi mekânla hem de yazarla ilgili toplumdaki farkındalığı artırma yönünde çalışmalar gerçekleştirdikleri görülmektedir. 
Aşiyan Müzesi, Kültür ve Turizm Bakanlığı ve diğer müzelerle sürekli iletişim içinde olduklarını belirten tek müzedir. Özellikle İl Kültür Müdürlügünün yaptığı, özel müzelerle devlet müzelerini buluşturan projeler doğrultusunda müzelerle bir paylaşım doğduğu belirtilmiştir. Bunun dışında edebi mekânların birçoğunun belediyeye bağlı kurumlar olması nedeniyle yerel paydaşlarla ilişkilerinin istenilen düzeyde olduğunu söylemek mümkündür. Ayrıca birçok edebi mekânın resmi ya da özel kurumlar ve çeşitli sivil toplum kuruluşlarıyla işbirliği ve destek anlamında iletişimi mevcuttur.

Kurumlarla iletişim dişında toplumla bütünleşmek de modern müzecilik açısından önemli bir konudur. Necati Cumalı Anı ve Kültür Evinde zemin katta çeşitli kaynak kitapların bulunduğu halka açık bir kütüphane yer almaktadır. Öğrenciler burada araştırma yapabilmekte ve personel de kendilerine yardımcı olmaktadır. Bu, hem modern müzeciliğin eğitim fonksiyonu açısından hem de toplumun müzeyle yakınlaşması açısından önemli bir unsurdur. Namık Kemal Evinde de çok geniş bir Namık Kemal arşivi bulunmaktadır. Evin yetkilisi, Namık Kemal'in ve onu anlatan pek çok eserin de toplanmasıyla buranın Türkiye'deki en geniş Namık Kemal arşivi olduğunun altını çizmiştir. Ziyaretçilere kitap, dergi gibi kaynakların temin edilebildiği de belirtilmiştir. Toplumla bütünleşme adına önemli bir uygulama olmasının yanı sıra Namık Kemal Evinin bu anlamdaki bir diğer özelliği de evde sergilenen pek çok objenin Tekirdağlı vatandaşların hediyeleriyle oluşturulmuş olmasıdır. Bu anlamda hem Tekirdağlı vatandaşların müzeyi benimsediği hem de müzenin toplumsallık işlevini yerine getirdiği söylenebilir. Sergilenen bu eşyaların altına hediye eden vatandaşların isminin yazılmış olmasının da önemli bir ayrıntı olduğunu belirtmek gerekir. Benzer bir uygulama Rıfat Ilgaz Kültür ve Sanat Evinde de yapılmaktadır. Bu mekândaki geleneksel kültürü yansıtan objeler de Cideli vatandaşların hediyeleriyle bir araya getirilmiştir. Namık Kemal Evinde bulunan bir oda da Tekirdağ' $1 n$ önemli şahsiyetleri için düzenlenmiştir. Bu odanın asıl teması, Tekirdağ’a hizmet etmiş tüm önemli isimleri bir arada bulundurarak onların hatıralarını yaşatmak ve ziyaretçilere şehir için önemli olan bu simalar hakkında bilgilendirme yapmaktır.

Her edebi mekân çeşitli etkinliklere ev sahipliği yapmaktadır. Necati Cumalı Kültür ve Sanat Evinde Necati Cumalı'yı anma etkinlikleri, fotoğraf sergileri, şiir dinletileri gibi çeşitli etkinlikler gerçekleştirilmektedir. Namık Kemal Evinde özellikle Namık Kemal haftasında aralık ayı içerisinde Namık Kemal kültürel etkinlikleri düzenlenmektedir. Ayrıca evin bahçe katında bulunan Mehmet Serez Sergi Salonunda da resim sergileri ve çeşitli kültürel faaliyetler gerçekleştirilebilmektedir. Sait Faik Abasıyanık Müzesi Adalar Belediyesi ile birlikte Sait Faik' in doğum ve ölüm yıl dönümlerinde Burgazada'da etkinlikler gerçekleştirmektedir. Müzenin alt katında bulunan, yaklaşık 20-30 kişinin ağırlanabildiği etkinlik salonunda da yazar ağırlama ya da Burgazadalı çocuklara öykü atölyesi şeklinde etkinlikler düzenlenmektedir. Ayrıca Adalar Sokak Festivali gibi Adalar'da gerçekleşen her etkinliğe de müze olarak katkı sunulduğu belirtilmiştir. Orhan Kemal Müzesinde müze binasında etkinlik gerçekleştirilemiyor olsa da müze olarak Türkiye çapında pek çok etkinliğe imza atılmaktadır. Örneğin Çukurova Belediyesinin düzenlediği Orhan Kemal Edebiyat Festivali'ne konuşmacı, sanatçı 
desteği sağlanması ya da Çukurova Edebiyatçılar Derneğinin Orhan Kemal Öykü Ödülü organizasyonunun desteklenmesi gibi. Ayrıca Sayın Işık Öğütçü pek çok televizyon programına ya da Türkiye'nin çeşitli illerinde düzenlenen konferans, panel gibi çeşitli etkinliklere katılarak müzenin daha görünür kılınmasında aktif rol oynamaktadır. Aşiyan Müzesi de çok sayıda etkinliğe imza atan bir edebi mekân olarak dikkat çekmektedir. Müze bünyesinde şiir günleri, geçici sergiler, festival, imza günleri, sempozyumlar gibi çok çeşitli sanatsal ve kültürel etkinlikler gerçekleştirilmektedir. Geleneksel olarak her yıl 19 Ağustos’ta Tevfik Fikret'i Anma Töreni müze bahçesinde Tevfik Fikret'in mezarının başında yapılmaktadır. Benzer şekilde Tevfik Fikret'in doğum günü olan 24 Aralık tarihinde de geleneksel etkinlikler düzenlenmektedir. Ayrıca müze zaman zaman fotoğraf grupları, kitap okuma grupları gibi çok çeşitli toplulukları da ağırlamaktadır. Yahya Kemal Müzesi, alan olarak küçük bir müze olduğundan müzenin etkinlik gerçekleştirmeye müsait olmadığı belirtilmiştir. Ancak İl ve İlçe Milli Eğitim Müdürlükleri ile başlatılan projeler doğrultusunda müze olarak okullarda Yahya Kemal'i tanıtıcı etkinlikler gerçekleştirilmektedir. Bunun yanı sıra okulların düzenledikleri programlara da fotoğraf, video, konuşmacı gibi çeşitli konularda destek verilmektedir. Yahya Kemal'in ölüm yıl dönümlerinde her y1l bir okul ile birlikte tören düzenlenmektedir. Yazarın 60. ölüm yıldönümü olan 2018'de Yahya Kemal Beyatlı Sempozyumu düzenlenmiştir. Rıfat Ilgaz Kültür ve Sanat Evi ise her yıl temmuz ayında "Cide Rıfat Ilgaz Sarı Yazma Kültür ve Sanat Festivali”ne ev sahipliği yapmaktadır. Evin gerçekleştirdiği başka bir etkinlik bulunmamaktadır.

Pazarlama, tanıtım ve sosyal medya: Modern müzeciliğin gerekli unsurlarından biri de müzelerin bilgiye erişimi olanaklı kılarak müze ve etkinlikler hakkında tanıtım yapılması suretiyle toplumda müzeye karşı olan farkındalığın artırılmasıdır. Bu yüzden müzecilikte pazarlama ve tanıtım çalışmaları çok önemli bir konumda olup bu çalışmaların ayrı bir birim tarafından üstlenilmesi gerekmektedir. Günümüzde teknolojinin gelişmesi ve hedef kitleye daha kolay erişilebilirliğin sağlanması gibi nedenlerle tanıtım çalışmalarında internet siteleri ve sosyal medya mecralarının rolü büyüktür. Ancak edebi mekânlarda pazarlama ve tanıtım çalışmaları için ayrı bir birimin olmadığı ve internetin ya da sosyal medyanın çoğu edebi mekânda aktif bir şekilde kullanılmadığı görülmektedir.

Edebi mekânların çoğu tanıtım amaçlı olarak yazılı materyalleri kullanmaktadır. Birçok edebi mekân broşür bastırmış, bazıları bu broşürleri yabancı dilde de hazırlatmıştır. Namık Kemal Evinde yazılı materyal olarak ev tarafından bastırılan İbret Gazetesi bulunmaktadır. Aşiyan Müzesi broşürlerin yanı sıra çeşitli etkinlikler zamanında afişler de bastırmaktadır.

Edebi mekânlardan sadece Sait Faik Abasıyanık Müzesi ve Aşiyan Müzesinin web sayfaları bulunmaktadır. Bu web sayfalarında hem yazarı ve edebi hayatını tanıtıcı hem de müze ve etkinlikler hakkında bilgilendirici paylaşımlar bulunmakta olup sürekli güncellemeler yapılmaktadır. Yahya Kemal Müzesi adı altında bir web sayfası bulunmamakta ancak müzenin bağlı bulunduğu İstanbul Fetih Cemiyetinin web sayfasında müze ve etkinlikler hakkında paylaşımlar yapılmaktadır. 
Sait Faik Abasıyanık Müzesi aynı zamanda sosyal medya mecralarını da etkin bir şekilde kullanmaktadır. Müzenin Facebook, Twitter ve Youtube mecralarında hesabı olup bu sayfalardan hem müze ve yazarla ilgili bilgilerin hem de güncel edebiyat haberlerinin paylaşımı yapılmaktadır. Aşiyan Müzesinin Facebook, Instagram ve Twitter hesapları mevcuttur ancak Twitter hesabı güncel olmayıp uzun süredir paylaşım yapılmamıştır. Namık Kemal Evinin Facebook ve Instagram sayfaları, Yahya Kemal Müzesinin de Instagram sayfası bulunmaktadır. Orhan Kemal Müzesinin müze adıyla Facebook ve Instagram sayfaları mevcuttur. Ancak Işık Öğütçü kendi Facebook, Instagram ve Twitter hesaplarından müzeyle ilgili güncel paylaşımlarda bulunmaktadır. Necati Cumalı Anı ve Kültür Evi ile Rlfat Ilgaz Kültür ve Sanat Evinin ise hiçbir sosyal medya mecrasında hesabı olmayıp sadece ziyaretçilerin etiketledikleri fotoğraflar aracılığıyla sosyal medyada görünür olabilmektedirler.

Tanıtım amacıyla yapılan etkili çabalardan biri olan reklam çalışmalarına edebi mekânların hem bütçesi elvermemekte hem de başka bir kuruma ya da derneğe bağlı olduklarından bu konuda karar mercii olamamaktadırlar. Bu kapsamda Aşiyan Müzesi ve Yahya Kemal Müzesi, İstanbul metrosunda yer alan ModyoTV'de tanıtımlarının yer aldığını belirtmişlerdir. Ancak edebi mekânlara yerel, ulusal hatta uluslararası basının da ilgisi gün geçtikçe artmakta ve zaman zaman bu mekânlarda program ya da belgesel çekimleri gerçekleştirilmektedir. Bu programların çoğu internet ortamında da izlenebilmekte ve dolayısıyla bu mekânların tanıtımına katkı sağlamaktadırlar. Benzer şekilde seyahat bloglarında da edebi mekânlarla ilgili yazılar paylaşılmaktadır. Ayrıca yine tanıtımın önemli bir unsuru olarak Aşiyan Müzesi uluslararası yarışmalara katıldığını da belirtmiştir.

Bazı edebi mekânlarda yazarların kitaplarının satışı da yapılmaktadır. Örneğin Sait Faik Abasıyanık Müzesi, hem kitap satışı hem de çeşitli hediyelik eşya satışı gerçekleştirmektedir. Bir başka örnek ise Orhan Kemal Müzesidir. Müzeye bağlı olan ve müzenin altında bulunan İkbal Kahvesinde hem yazarın tüm eserlerinin satışı yapılmakta hem de ziyaretçiler sohbet ortamında müzeyle ve Orhan Kemal ile ilgili detaylı bilgiler alabilmektedirler.

\section{Sonuç}

Türkiye'deki edebi mekânların modern müzecilik açısından incelendiği bu çalışmada yöneticilerin; müzeleri günümüz koşullarına uygun hale getirmek, toplumla yakınlaştırmak ve müzelere dair farkındalığı artırmak yönünde çabalarının olduğu ancak bu yolda çeşitli engellerle karşılaştıkları ortaya çıkmıştır. Bu engellerden en önemlisi bütçe sorunudur. Edebi mekânlar, genellikle belediye, dernek gibi birimlere bağlı olmalarından ve kar amacı gütmeyen kuruluşlar olarak hizmet vermelerinden dolayı yüksek bir bütçeye sahip değillerdir. Bu yüzden yeni teknolojilerin müze bünyesinde kullanımı, etkin tanıtım ve reklam çalışmalarının yapılması gibi maliyet gerektiren çalışmalar edebi mekânları zorlamaktadır.

Başka birimlere bağlı olmanın edebi mekânları etkilediği bir diğer durum da karar verme aşamasında ortaya çıkmaktadır. Mekân yöneticileri; herhangi bir etkinlik, tanıtım ya da işbirliği gibi konularda tek başlarına karar verme mercii olmadıkları için bağlı bulundukları birimlerden izin alma ya da onların aldığı kararları uygulama durumunda kalabilmektedirler. Bu durum da edebi mekânların gelişiminde engel oluşturan unsurlardan biridir. 
Kâr amacı gütmeyen kuruluşlar olarak edebi mekânlarda personel sayısının az olması da yapılmak istenen pek çok işin geri plana atılmasına neden olan önemli unsurlardan biridir. Edebi mekânların çoğunda bir ya da iki personel bulunmakta olup bu personel ancak rutin işlerle ilgilenebilmektedir. Edebi mekânlarda modern müzecilikte olması gereken eğitim birimi uzmanı, sosyal medya uzmanı gibi pozisyonların bulunmuyor oluşu da bu mekânların profesyonel bir biçimde yönetiminin önünde bir engel teşkil etmektedir. Öte yandan mekânla ilgili çeşitli sıkıntılar ve bu sıkıntıların giderilmesinde yaşanan bürokratik süreçler çoğu zaman sorunlar oluşturabilmektedir. Edebi mekânların çoğunun tarihi yapılar olması, restorasyon ve çeşitli tadilat işlemlerini gerektirmektedir. Yazarların özgün eşyalarının ve belgelerinin korunabilmesi için bu işlemlerin de ayrı bir uzmanlık gerektirmesi ve gerekli araştırmalar yapılarak bu işlerin yapılabilmesi söz konusudur.

Bu mevcut sorunlara rağmen edebi mekânlar modern müzeciliğin gereklerini yerine getirmek için çaba göstermektedirler. Sunum ve anlatım teknikleri açısından, bahsi geçen problemlerden dolayı teknolojik imkânları her mekân takip edemese de münferit ya da grup ziyaretçilerine kişisel rehberlik hizmeti uygulayarak en güçlü iletişim yoluyla bilgi verme fonksiyonunu yerine getirmektedirler. Eğitim alanında da her edebi mekânın iyi düzeyde olduğunu söylemek mümkündür. İl Milli Eğitim Müdürlükleri ile yapılan protokoller aracılığıyla edebi mekânlar düzenli olarak okulları ağırlamakta, kimi zaman da kendileri okullara giderek çeşitli etkinliklerde yazar ve müze hakkında bilgilendirme yapmaktadırlar. Koruma ve restorasyon alanında bir değerlendirme yapıldığında; yazarın doğduğu ya da hayatının bir kısmını geçirdiği edebi mekânlar, restorasyon çalışmalarında mekânın orijinal haline sadık kalma konusunda büyük bir gayret göstermişlerdir. Yazarların bizzat şahsına ait olan objelerin ve belgelerin sergilenmesi konusunda gerekli koruma önlemleri de alınmaya çalışılmaktadır.

Modern müzeciliğin diğer iki unsuru olan "araştırma, iletişim ve etkinlikler" ile "pazarlama, tanıtım ve sosyal medya" alanlarında da edebi mekânların çabaları olmakla birlikte yukarıda bahsedilen nedenlerden dolayı bu iki alanda geride kaldıkları söylenebilir. Bu konularda yapılacak işıler hakkında daha çok edebi mekânların bağlı bulundukları birimler nezdinde kararlar alınmakta ve hiç şüphesiz edebi mekân için ayrılan bütçe bu konuda önemli bir belirleyici olmaktadır. Bu anlamda edebi mekânların daha çok tanınmasını ve toplumla yakınlaşmasını sağlayacak çalışmalar için mekân yöneticilerinin sorumluluğunun artırılması ve karar alma mekanizmasının daha özerk bir şekilde çalıştırılması önem arz etmektedir. Diğer kurumlarla, müzelerle ya da çeşitli işletmelerle yapılacak işbirlikleri konusunda bürokrasinin ortadan kaldırılması, daha etkin ve verimli çalışmaların yapılmasını sağlayacaktır.

Edebi mekânların, başta bulundukları şehirler olmak üzere ülkelerin bir kültürel miras değeri oldukları unutulmamalıdır. Yazarların bıraktığı edebi mirası yaşatan edebi mekânların, bir yandan bu mirasın özgün haliyle gelecek nesillere aktarılması hususundaki çalışmalara ağırlık vermeleri bir yandan da toplumun değişen beklentilerine uyum sağlayan ve günümüzün çağdaş teknolojilerini mümkün olduğunca barındıracak biçimde profesyonel bir yönetime kavuşmaları gerekmektedir. 


\section{Kaynaklar}

Atagök, T. (2010). Müzecilik ve Türk müzeciliği. Ege Mimarlı,, S. 74, ss. 8-13.

Barlas Bozkuş, Ş. (2014). Kültür ve sanat iletişimi çerçevesinde Türkiye'de sanal müzelerin gelişimi. The Journal of Academic Social Science Studies, S. 26, ss. 329-344.

Boyraz, B. (2013). Müze teknolojileri ve sergileme farkl11ıları. Ídil Sanat ve Dil Dergisi, S. 2(8), ss. 113-128.

Erbay, M. (2011). Müzelerde sergileme ve sunum tekniklerinin planlanması. İstanbul: Beta.

Karabıyık, A. (2007). Çağdaş sanat müzeciliği kapsamında Türkiye'deki müzecilik hareketlerine bir bakış. Yayımlanmamış Yüksek Lisans Tezi. Erzurum: Atatürk Üniversitesi.

Keleş, V. (2003). Modern müzecilik ve Türk müzeciliği. Atatürk Üniversitesi Sosyal Bilimler Enstitüsü Dergisi, S. 2(1-2), ss. 1-17.

Kervankıran, İ. (2014). Dünyada değişen müze algısı ekseninde Türkiye'deki müze turizmine bakış. Turkish Studies, S. 9, ss. 345-369.

Okan, B. (2015). Günümüzde müzecilik anlayışı. Sanat ve Tasarım Dergisi, S. 5(2), ss. 187-198.

\section{Elektronik kaynaklar}

Altunbaş, A. ve Özdemir, Ç. (2012). Çağdaş müzecilik anlayışı ve ülkemizde müzeler. Ankara: Kültür ve Turizm Bakanlığı Teftiş Kurulu Başkanlığı. (Erişim: 14.08.2019) https://teftis.ktb.gov.tr/ Eklenti/4655,makale.pdf

Ersoy, U. (2016). Türk müzeciliğinde mevcut durum analizi. Müze Profesyonelleri Projesi. (Erişim: 14.08.2019) http://cagdasmuzebilim.ankara.edu.tr/wp-content/uploads/sites /384/2017/02/ Q1.Mevcut-Durum-Analizi.pdf

ICOM (2007). Development of the museum definition according to Icom statutes (2007-1946). (Erişim: 29.11.2019) http://archives.icom.museum/hist_def_eng.html

İstanbul İl Kültür ve Turizm Müdürlüğü (2019). Aşiyan müzesi. (Erişim: 22.07.2019) https://istanbul. ktb.gov.tr/TR-165467/asiyan-muzesi.html 